\title{
Amoxapine as an Atypical Antipsychotic: A Comparative Study Vs Risperidone
}

\author{
Rogelio Apiquian*, 1,4, Ana Fresan ${ }^{2}$, Rosa-Elena Ulloa, ${ }^{3,4}$, Camilo de la Fuente-Sandoval ${ }^{4}$, \\ Miguel Herrera-Estrella ${ }^{5}$, Alejandra Vazquez ${ }^{4,5}$, Humberto Nicolini ${ }^{4,6}$ and Shitij Kapur ${ }^{7}$ \\ 'Department of Psychiatry, National Institute of Neurology and Neurosurgery Manuel Velasco Suarez, Mexico City, Mexico; ${ }^{2}$ Clinical Research \\ Division, National Institute of Psychiatry Ramón de la Fuente, Mexico City, Mexico; ${ }^{3}$ Child Psychiatric Hospital JN Navarro, Mexico City, Mexico; \\ ${ }^{4}$ Carracci Medical Group, Mexico City, Mexico; ${ }^{5}$ Psychiatric Hospital Fray Bernardino Alvarez, Mexico City, Mexico; ${ }^{6}$ Department of Genomic \\ Medicine, Mexico City University, Mexico City, Mexico; ${ }^{7}$ Schizophrenia Program and the Department of Psychiatry, University of Toronto, Toronto, \\ ON, Canada
}

\begin{abstract}
Amoxapine is marketed as an antidepressant. However, its invitro profile, receptor occupancy and preclinical effects are very similar to atypical antipsychotics. Amoxapine has also shown efficacy as an atypical antipsychotic in open trials. The objective of this study was to compare the antipsychotic and side effect profile of amoxapine and risperidone in a randomised assignment, standardized dosing, doubleblind trial of acutely psychotic patients with schizophrenia. A total of 48 schizophrenic patients were enrolled and randomized in a double-blind 6-week trial to receive either risperidone (up to $5 \mathrm{mg} /$ day) or amoxapine (up to $250 \mathrm{mg} /$ day). Positive, negative, affective symptoms and motor side effects were measured using standardized weekly assessments. Prolactin levels were also determined at baseline and at the end of the study. A total of 39 patients (amoxapine, $n=22$; risperidone, $n=21$ ) completed the trial. Both pharmacological treatments, amoxapine $228.0 \mathrm{mg} /$ day $(\mathrm{SD}=34.6)$ and risperidone $4.5 \mathrm{mg} /$ day $(\mathrm{SD}=0.7)$, showed equivalent improvement in positive, negative, and depressive symptoms. Amoxapine was associated with less EPS and less prolactin elevation than risperidone. These data support previous reports about the efficacy of amoxapine as an atypical antipsychotic. Since amoxapine is off-patent, it may be a valuable low-cost alternative to new atypical antipsychotics, particularly in low-income countries where the majority of the patients are still treated with typical antipsychotics.
\end{abstract}

Neuropsychopharmacology (2005) 30, 2236-2244. doi:I 0.1038/sj.npp. I 300796; published online 8 June 2005

Keywords: amoxapine; risperidone; schizophrenia; atypical; antipsychotic

\section{INTRODUCTION}

The introduction of atypical antipsychotics represents an advance in the treatment of schizophrenia because they are generally better tolerated than conventional antipsychotics and have been associated with improved efficacy in certain domains (Kinon and Lieberman, 1996). However, they are many times more expensive than older options, thus practically inaccessible for most patients with schizophrenia around the world. This has led to search for pharmacological alternatives like the minimum effective doses of conventional antipsychotic drugs (Emsley et al, 1999; McEvoy et al, 1991; Oosthuizen et al, 2001) or the study

*Correspondence: Dr R Apiquian, Department of Psychiatry, National Institute of Neurology and Neurosurgery Manuel Velasco Suarez, Av. Insurgentes Sur 3877, Mexico City, 14296 Mexico, Tel: 5255 56। I5822, Fax: 5255 56150067,

E-mail: rogelioapiquian@yahoo.com.mx

Received 3 March 2005; revised 3 May 2005; accepted 4 May 2005 Online publication: 10 May 2005 at http://www.acnp.org/citations/ Npp05 I005050 I52/default.pdf of older and off-patent drugs for possible atypical antipsychotic efficacy.

Given our interest in this question, we chose to examine amoxapine's therapeutic potential as an atypical antipsychotic, given that first, amoxapine is a close chemical relative of clozapine, a dibenzazepine (Greenblatt et al, 1978); second, as an antidepressant it was noted to be especially effective in psychotic depression (Anton and Burch, 1990; Anton and Sexauer, 1983; Lydiard and Gelenberg, 1981); third, it blocks serotonin 5HT2 and dopamine D2 receptors in normal healthy volunteers, and in vitro its 5HT2/D2 and D4/D2 ratios are similar to those of clozapine (Kapur et al, 1999; Stockmeier et al, 1993), and finally, at a preclinical level, amoxapine, like risperidone, olanzapine and clozapine, shows a wide therapeutic window between the efficacy/mesolimbic doses $v s$ doses at which it causes catalepsy/striatal effects (Greenblatt et al, 1978; Wadenberg et al, 2000).

In keeping with this, a prospective open-label study with 17 schizophrenic patients showed that amoxapine was associated with a clinically significant improvement in 
positive, negative, and general symptoms. Also, a trend towards improvement in independently measured affective symptoms and a low propensity for extrapyramidal side effects was observed (Apiquian et al, 2003).

Given the strong rationale and the encouraging results from the open-label study, the purpose of this study was to test the 'atypical antipsychotic' potential of amoxapine by comparing it to the leading atypical antipsychotic, risperidone, in a double-blind clinical evaluation. The main hypotheses of the present study were: (a) amoxapine would show an antipsychotic effect comparable to risperidone's; (b) amoxapine would not show treatment emergent extrapyramidal symptoms (EPS) and would be comparable to risperidone in this regard; and (c) amoxapine would show a lesser degree of prolactin elevation and weight gain than risperidone.

\section{METHODS}

\section{Study Setting}

The study was conducted in accordance with Good Clinical Practices and the World Medical Association Declaration of Helsinki, Edinburgh 2000. The study protocol was approved by the Institutional Review Boards of the Centre for Addiction and Mental Health at the University of Toronto and Carracci Medical Group, Mexico City. Written informed consent was obtained after the procedures had been fully and detailed explained to patients.

\section{Subjects}

The subjects were recruited from the inpatient, emergency, and outpatient services of two public hospitals at Mexico City. Patients were included in the study if they met the following criteria: (1) Men and nonpregnant, nonlactating women aged between 18 and 50 years; (2) DSM-IV criteria for schizophrenia; (3) free of concomitant medical or neurological illness (as per review of systems, general physical examination, and a baseline laboratory evaluation); (4) free of DSM-IV current substance abuse or a history of substance dependence in the last 6 months; and (5) baseline PANSS positive syndrome score at least 16 , with two items scoring at least four. Patients were excluded if (1) they had a history of bipolar disorder; (2) a high risk for suicide or high risk for agitation/violence; (3) they were pregnant or child-bearing age women who were not practising reliable forms of contraception; (4) were refractory to antipsychotics (defined as those who have received more than two typical or atypical neuroleptics, at doses equivalent to $5 \mathrm{mg} /$ day of haloperidol, for at least 6 weeks each with little significant clinical improvement; and (5) had a history of previous adverse response to risperidone.

\section{Study Design and Procedures}

This was a 6-week, randomized, double-blind, flexible, dose-controlled study. Patients on oral antipsychotics prior to entry into the study participated in a 3-day washout, while patients receiving depot antipsychotic therapy prior to study entry underwent in a washout period of one cycle plus 1 week. After the baseline evaluation, subjects were titrated to the starting dose of $150 \mathrm{mg} /$ day of amoxapine or $3 \mathrm{mg} /$ day of risperidone within 3 days. The dose ratio of $50: 1$ was chosen based on PET data which suggested that this ratio would give raise to similar effects on 5-HT2 and D2 receptors (Kapur et al, 1999). The dose was held at 150 or $3 \mathrm{mg}$ till day 14. Patients who showed 'much improvement' (reflected by a score of $>3$ on a CGI-Improvement) by day 14 of treatment continued with this dose for the rest of the study. Those patients who showed 'no' or 'little' improvement (reflected by a score of $<2$ on a CGIImprovement) have their dose increased to $200 \mathrm{mg}$ /day of amoxapine or $4 \mathrm{mg} /$ day of risperidone at day 14 and if necessary $250 \mathrm{mg} /$ day of amoxapine or $5 \mathrm{mg}$ /day of risperidone on day 21 . Symptoms and safety assessments were obtained at screening, baseline, and throughout the double-blind treatment phase.

Psychotropic drug administration other than the prescribed study medication was prohibited throughout the study except for benzodiazepines prescribed for anxiety, insomnia, or emerging agitation as deemed necessary by the investigator. The maximum daily benzodiazepine dose was not to exceed the equivalent of $4 \mathrm{mg} / \mathrm{day}$ of lorazepam. Anticholinergic drugs for EPS were permissible if clinically indicated. All concomitant medication use was recorded.

\section{Assessments}

Efficacy. Psychopathology was assessed by using the Positive and Negative Syndrome Scale (30 items, 1-7 severity scale) (Kay et al, 1990), the Calgary Depression Scale for Schizophrenia (CDSS) (Addington et al, 1996), and the Clinical Global Impression - Severity of Illness (CGI-S) and Improvement of Illness (CGI-I) scales (Guy, 1976). The reliability of these scales, as measured using intraclass correlation coefficients, were between 0.80 and 0.91 , as established in previous studies of similar populations in our Centre (Apiquian et al, 1997). The CGI-S was administered at baseline and weekly, the CGI-I was rated weekly, while the PANSS and the CDSS were administered at baseline, weeks 2,4 , and 6 . The response criteria a priori specified in the study required $a \geqslant 30 \%$ decrease from baseline in PANSS total score to study end point.

Safety. Extrapyramidal side effects were evaluated at baseline, weeks 2, 4, and 6 using the Simpson-Angus Scale (SAS) (Simpson and Angus, 1970) and the Barnes Akathisia Rating Scale (BAS) (Barnes, 1989). The Abnormal Involuntary Movement Scale (AIMS) (National Institute of Mental Health, 1975) was used at baseline and at the end point of the study.

Further safety investigations included electrocardiogram (EKG), vital signs, and body weight measurement. Laboratory testing of blood included determination of fasting total glucose and prolactin assays. Prolactin levels were determined using an automated two-site chemiluminometric immunoassay with a minimum detectable limit of $0.3 \mathrm{ng} / \mathrm{ml}$ and a coefficient of variance of 3.6-4.5\% (ACS, CibaCorning Diagnostics). These measurements were determined at baseline, week 3 and at the end of the study. 


\section{Statistical Procedures}

Demographic and clinical characteristics description was done with frequencies and percentages for categorical variables and with means and standard deviations (SD) for continuous variables. Chi square test $\left(\chi^{2}\right)$ was used for categorical contrasts. Patients were included in the analysis of mean change from baseline to last-observation-carriedforward (LOCF) end point if the patient had received at least one dose of double-blind medication and had at least one efficacy measurement during the study. In addition, patients who completed the study were included in an observed-cases (OC) using analysis of covariance (ANCOVA) model, which contained baseline status as covariate, and the treatment as the effect of interest. The primary efficacy parameter was the change in PANSS total score from baseline to end point. Secondary efficacy parameters included change from baseline to end point in the CGI-S score, end point values of the CGI-I score, and change from baseline to end point in the CDSS score. The analysis of safety measures included changes in vital signs, body weight, EKG, clinical laboratory tests, BAS, SAS, and AIMS scores. Statistical tests were two-sided and performed at 0.05 significance level.

\section{RESULTS}

\section{Patients}

A total of 48 schizophrenic patients were recruited and randomized; five patients were lost at the first week of the follow-up (amoxapine $n=3$, risperidone $n=2$ ) and were excluded from analysis as there was no postbaseline measurement in these subjects. The remaining 43 patients were assigned to amoxapine $(n=22)$ or risperidone $(n=21)$ treatment. Completion rates between the risperidone-treated $(n=20,95.2 \%)$ and the amoxapine-treated $(n=19,86.4 \%)$ patients were not significantly different $\left(\chi^{2}=1.00\right.$, df $\left.1, p=0.31\right)$. Two patients from the amoxapine group and one from the risperidone group failed to complete the study because of lack of efficacy while one patient from the amoxapine group did not consent after week 4.

A total of $51.2 \%(n=22)$ of the sample were men and $48.8 \%(n=21)$ were women. The mean age of the patients was 30.8 years $(\mathrm{SD}=9.0$, range $18-50$ years). The educational level was 10.2 years $(\mathrm{SD}=3.5$, range $0-18$ years), $93.0 \%(n=40)$ were single and $53.5 \%(n=23)$ were unemployed at their recruitment. Diagnoses of the sample were paranoid schizophrenia $(69.8 \%, n=30)$, undifferentiated schizophrenia $(16.3 \%, n=7)$, and disorganized schizophrenia $(14.0 \%, n=6)$. The mean length of illness was 330.0 weeks $(\mathrm{SD}=367.4$, range $24-1872$ weeks).

Prior to the trial, four (18.2\%) patients from the amoxapine group and four (19.1\%) from the risperidone group were naive to antipsychotic treatment, while nine (40.9\%) patients from the amoxapine group were under atypical antipsychotic treatment (amisulpride $=$ two, sulpiride $=$ two, risperidone $=$ five) in comparison to nine $(42.8 \%)$ from the risperidone group (amisulpride $=$ two, sulpiride $=$ three, risperidone $=$ three, olanzapine $=$ one) . Nine patients (40.9\%) from the amoxapine group and eight
(38.1\%) from the risperidone group were under haloperidol treatment. The patients with previous antipsychotic treatment were included if they had a lack of improvement or worsening of their symptoms on their previous medication. Patients who had previously been treated with risperidone were only included if they had not failed the treatment (ie their current exacerbation was due to noncompliance).

There were no significant differences between the two treatment groups on baseline demographic characteristics. Both groups were also comparable in terms of some illness features at baseline (Table 1). For patients included in the $\mathrm{OC}$ analysis, the mean amoxapine dose at the end of week 3 was $178.9 \mathrm{mg} /$ day $(\mathrm{SD}=25.3)$, at week 4 of $223.6 \mathrm{mg} /$ day $(\mathrm{SD}=34.8)$, and at the end of the study was $228.0 \mathrm{mg} /$ day $(\mathrm{SD}=34.6)$, while for risperidone the mean doses were $3.7 \mathrm{mg} /$ day $(\mathrm{SD}=0.5), 4.4 \mathrm{mg} /$ day $(\mathrm{SD}=0.7)$, and $4.5 \mathrm{mg} /$ day $(\mathrm{SD}=0.7)$ at weeks 3,4 , and 6 , respectively.

\section{Efficacy Data}

Mean baseline and change from baseline to LOCF end point efficacy rating scale scores in both treatment groups are shown in Table 2A, and mean baseline and change from baseline to week 6 efficacy rating scale scores for completers in both treatment groups are shown in Table 2B. In both LOCF and OC analyses, amoxapine and risperidone were associated with similar improvement in psychotic symptoms as measured by changes from baseline on the total PANSS, PANSS subscales, CGI-S, CGI-I, and depressive symptoms assessed by the CDSS. Although patients on the amoxapine group showed a higher score on the CDSS at baseline when compared to the risperidone group in the OC analysis $(t=2.23$, df $37, p=0.03)$, no statistically reliable differences emerged between groups in week 6 (amoxapine $=2.26, \mathrm{SD}=2.21$ vs risperidone $=1.25, \mathrm{SD}=$ 2.12) $(t=1.46$, df $37, p=0.15)$.

\section{Response Rate Analysis}

Using the $\geqslant 30 \%$ in PANSS total score response criteria, the LOCF response rate was $72.7 \%$ in the amoxapine group and $76.2 \%$ in the risperidone group $\left(\chi^{2}=0.06\right.$, $\left.\mathrm{df} 1, p=0.79\right)$. For completers, similar response rates were found in both treatment groups (amoxapine $78.9 \%$ vs risperidone $75.0 \%$ ) $\left(\chi^{2}=0.08\right.$, df $\left.1, p=0.77\right)$.

\section{Safety}

There were no clinically relevant differences in vital signs between treatment groups. Mean baseline and change from baseline to LOCF end point safety measures are shown in Table $3 \mathrm{~A}$, and mean baseline and change from baseline to week 6 safety measures for completers (OC) are shown in Table 3B. In the LOCF analysis, the risperidone-treated patients had significantly greater mean SAS scores than the amoxapine-treated patients at baseline $(t=2.54$, df 41 , $p=0.01$ ) and at the end of the study (amoxapine $=0.18$, $\mathrm{SD}=0.39 ; \quad$ risperidone $=1.48, \quad \mathrm{SD}=2.36) \quad(t=2.53, \quad 41$, $p=0.01)$. There were no significant baseline differences between the treatment groups in the OC analysis. Amoxapine was superior to risperidone for SAS mean change from baseline scores in the LOCF $(\mathrm{F}=6.62$, df $1, p=0.01)$, 
Table I Demographic and Clinical Characteristics between Treatment Groups

\begin{tabular}{|c|c|c|c|c|c|}
\hline & \multicolumn{2}{|c|}{ Amoxapine $(n=22)$} & \multicolumn{2}{|c|}{ Risperidone $(n=2 \mathrm{I})$} & \multirow[b]{2}{*}{ Statistic } \\
\hline & $n$ & $\%$ & $n$ & $\%$ & \\
\hline \multicolumn{6}{|l|}{ Gender } \\
\hline Male & 10 & 45.5 & 12 & 57.1 & $\chi^{2}=0.5, \mathrm{df} I, p=0.44$ \\
\hline Female & 12 & 54.5 & 9 & 42.9 & \\
\hline Married & 1 & 4.5 & 2 & 9.5 & $\chi^{2}=0.4, \mathrm{df} I, p=0.52$ \\
\hline Single & 21 & 95.5 & 19 & 90.5 & \\
\hline \multicolumn{6}{|l|}{ Employment status } \\
\hline Housewife & 6 & 27.3 & 3 & 14.3 & \\
\hline \multicolumn{6}{|l|}{ Schizophrenia type } \\
\hline Disorganized & 2 & 9.1 & 4 & 19.0 & \\
\hline Paranoid & 18 & 81.8 & 12 & 57.1 & $\chi^{2}=3.1, \mathrm{df} I, p=0.20$ \\
\hline \multirow[t]{2}{*}{ Undifferentiated } & 2 & 9.1 & 5 & 23.9 & \\
\hline & Mean & SD & Mean & SD & \\
\hline Age & 31.0 & 9.7 & 30.7 & 8.4 & $t=0.1, \mathrm{df} 4 \mid, p=0.91$ \\
\hline Years of education & 10.2 & 4.4 & 10.3 & 2.4 & $t=-0.09, \mathrm{df} 4 \mathrm{I}, p=0.92$ \\
\hline
\end{tabular}

Table 2 Mean Change from Baseline to LOCF End Point (A) and to Week 6 in Completers (B) in Efficacy Rating Scales

\section{(A) LOCF analysis}

\begin{tabular}{|c|c|c|c|c|c|}
\hline Test & \multicolumn{2}{|c|}{ Amoxapine $(n=22)$} & \multicolumn{2}{|c|}{ Risperidone $(n=2 I)$} & Statistic $^{\mathbf{a}}$ \\
\hline Baseline & 22.8 & 6.3 & 22.9 & 5.5 & \\
\hline Mean change & -9.8 & 7.0 & -9.5 & 7.8 & $F=0.03, d f I, p=0.86$ \\
\hline \multicolumn{6}{|l|}{ Negative PANSS } \\
\hline Baseline & 21.7 & 9.2 & 24.7 & 7.3 & \\
\hline Mean change & -6.4 & 9.1 & -8.4 & 7.2 & $F=0.00 I, d f I, p=0.98$ \\
\hline \multicolumn{6}{|l|}{ General PANSS } \\
\hline Baseline & 43.6 & 9.5 & 43.0 & 9.0 & \\
\hline \multicolumn{6}{|l|}{ Total PANSS } \\
\hline Mean change & -31.5 & 28.4 & -30.8 & 25.0 & $F=0.1 I, d f I, p=0.74$ \\
\hline
\end{tabular}


Table 2 Continued

\begin{tabular}{|c|c|c|c|c|c|}
\hline \multirow[b]{2}{*}{ Test } & \multicolumn{2}{|c|}{ Amoxapine $(n=22)$} & \multicolumn{2}{|c|}{ Risperidone $(n=2 I)$} & \multirow[b]{2}{*}{ Statistic $^{a}$} \\
\hline & Mean & SD & Mean & SD & \\
\hline \multicolumn{6}{|c|}{ Calgary Depression Scale } \\
\hline Baseline & 5.3 & 1.0 & 2.9 & 4.1 & \\
\hline \multicolumn{6}{|c|}{ Clinical Global Impression - Severity } \\
\hline Baseline & 5.3 & 1.0 & 5.3 & 0.8 & \\
\hline Mean change & -2.3 & 1.8 & -2.1 & 1.4 & $\mathrm{~F}=0.26, \mathrm{df} I, p=0.6 \mathrm{I}$ \\
\hline
\end{tabular}

(B) OC analysis

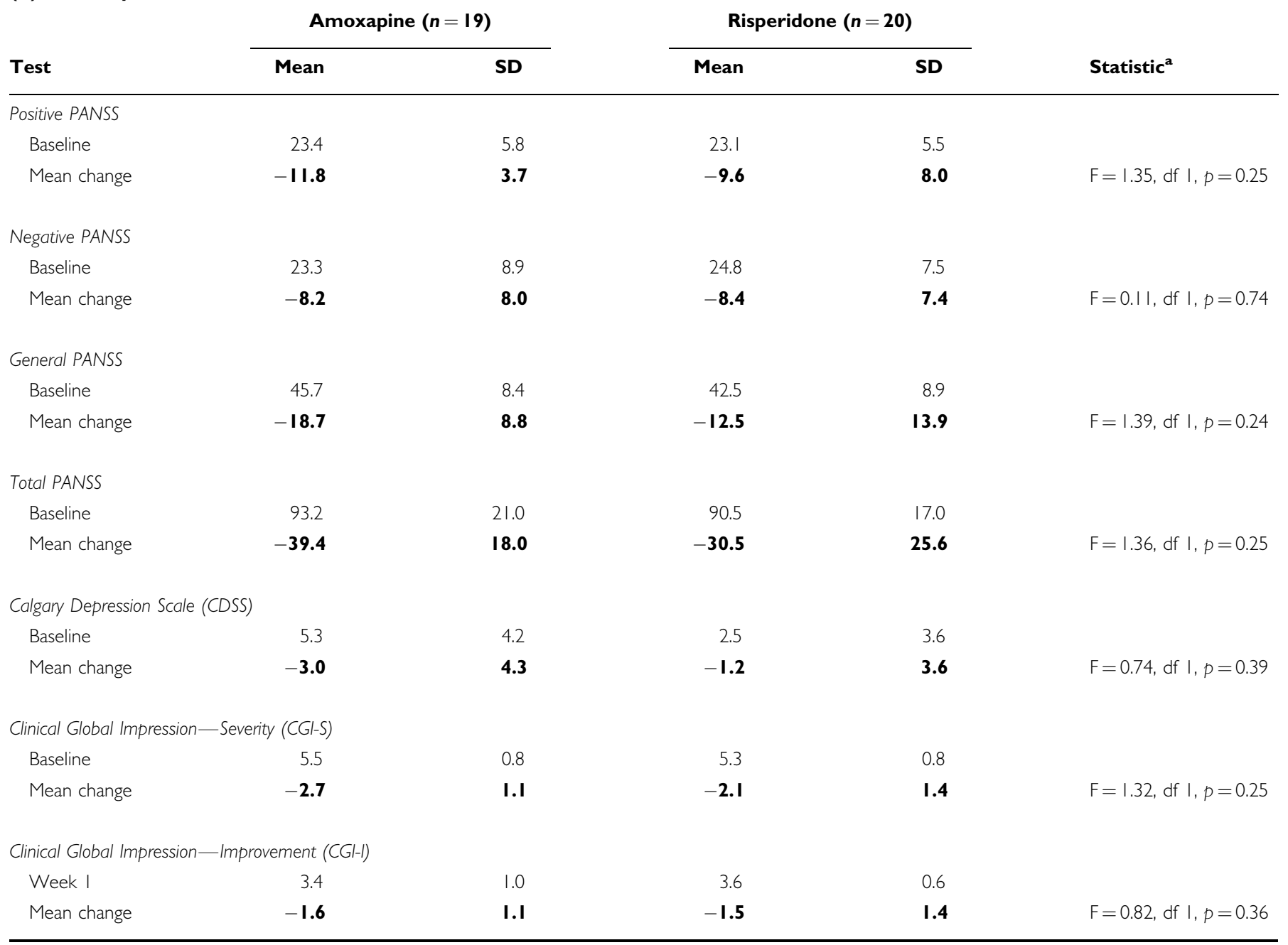

Bold values represent the mean score change from baseline to end point.

${ }^{a}$ Based on analysis of covariance adjusted for baseline score.

while a trend was observed in the $\mathrm{OC}$ analysis $(\mathrm{F}=3.68 \mathrm{df}$ $1, p=0.06)$. No significant differences between groups were observed for mean change in BAS or AIMS scores in the
LOCF and OC analyses. Similar rates of body weight gain and increased glucose levels were observed in both treatment groups in the LOCF and OC analyses. 
Table 3 Mean Change from Baseline to LOCF End Point (A) and to Week 6 in Completers (B) in Safety Measures

\section{(A) LOCF analysis}

\begin{tabular}{|c|c|c|c|c|c|}
\hline Test & \multicolumn{2}{|c|}{ Amoxapine $(n=22)$} & \multicolumn{2}{|c|}{ Risperidone $(n=21)$} & Statistic $^{\mathbf{a}}$ \\
\hline Baseline & 0.23 & 0.87 & 0.38 & 1.07 & \\
\hline Mean change & -0.04 & 0.99 & 1.09 & 1.84 & $\mathrm{~F}=6.62, \mathrm{df} I, p=0.0 \mathrm{I}$ \\
\hline Baseline & 1.0 & 2.39 & 0.57 & 2.18 & \\
\hline Mean change & -0.22 & 2.70 & 0.95 & 2.76 & $F=1.75, \mathrm{df} I, p=0.19$ \\
\hline \multicolumn{6}{|c|}{ Abnormal Involuntary Movement Scale score (AIMS) } \\
\hline Baseline & 0.68 & 1.46 & 1.05 & 2.52 & \\
\hline Baseline & 68.47 & 11.63 & 67.00 & 11.36 & \\
\hline Mean change & 1.05 & 2.42 & 1.30 & 2.06 & $F=1.36, d f I, p=0.25$ \\
\hline \multicolumn{6}{|c|}{ Glucose level (mg/dl) } \\
\hline Baseline & 81.00 & 8.43 & 84.57 & 16.86 & \\
\hline Mean change & 2.68 & 8.54 & 0.10 & 12.98 & $F=0.74, d f I, p=0.39$ \\
\hline \multicolumn{6}{|c|}{ Prolactin levels (ng/ml) } \\
\hline Baseline & 15.63 & 12.12 & 34.48 & 25.16 & \\
\hline Mean change & 5.59 & 25.49 & 6.07 & 36.31 & $F=0.82, d f I, p=0.36$ \\
\hline
\end{tabular}

\section{(B) OC analysis}

Amoxapine $(n=19)$

Test

Simpson-Angus Scale score

Baseline

Mean change

0.05

0.15

$\mathbf{0 . 5 0}$

1.38

1.72

$\mathbf{0 . 2 6}$

Mean change

Abnormal Involuntary Movement Scale score (AIMS)

Baseline

0.74

Mean change

$-0.26$

Body weight $(\mathrm{kg})$

Baseline

Mean change
68.02

1.04
1.56

1.72

11.52

2.59
Risperidone $(n=20)$

Mean SD

0.40

1.10

I.15

1.87

$F=3.68, d f I, p=0.06$
0.60

$\mathbf{0 . 5 5}$

1.10

$\mathbf{0 . 3 0}$

67.45

1.37
2.23

2.11

$F=0.26, d f I, p=0.6 I$
4.82 $F=0.87, d f I, p=0.35$

1.46

2.09

$F=1.36, d f I, p=0.25$ 
Table 3 Continued

(B) OC analysis

Amoxapine $(n=19)$

Test

(Mean

\section{Glucose level (mg/dl) \\ Baseline}

Mean change

Prolactin levels ( $\mathrm{ng} / \mathrm{ml}$ )

Baseline

Mean change

QTc prolongation (ms)

Baseline
Mean change

\subsection{6}

3.10

15.27

6.26

396.31

$-15.26$

SD

8.97

9.15

$12.6 \mid$

27.25
Risperidone $(n=20)$

$\begin{array}{ll}\text { Mean } & \text { SD } \\ \text { Statistic }^{\mathrm{a}}\end{array}$

Bold values represent the mean score change from baseline to end point.

aased on analysis of covariance adjusted for baseline score.

Mean serum prolactin levels were elevated above normal range at baseline in the risperidone group $(\mathrm{LOCF}=$ $34.48 \mathrm{ng} / \mathrm{ml}, \mathrm{SD}=25.16$; $\mathrm{OC}=33.29 \mathrm{ng} / \mathrm{ml}, \mathrm{SD}=25.19)$ and significantly different from the prolactin level observed in the amoxapine group $(\mathrm{LOCF}=15.63 \mathrm{ng} / \mathrm{ml}, \mathrm{SD}=12.12$; $\mathrm{OC}=15.27 \mathrm{ng} / \mathrm{ml}, \quad \mathrm{SD}=12.61) \quad(\mathrm{LOCF} \quad t=3.15, \quad \mathrm{df} \quad 41$, $p=0.01$; OC $t=2.80$, df $37, p=0.008$ ). On evaluation of individual subjects it was observed that this high serum prolactin level resulted from six patients in the risperidone group who had more than double the normal values even at baseline. The baseline mean prolactin level of these six patients $(\mathrm{LOCF}=68.9 \mathrm{ng} / \mathrm{ml} ; \mathrm{OC}=71.0 \mathrm{ng} / \mathrm{ml})$. All of them were on oral haloperidol treatment before the study (mean dose $=16.2 \mathrm{mg} /$ day). When these patients were excluded from the prolactin level analysis, no baseline differences were found between groups ( $\mathrm{LOCF}=$ amoxapine 15.6, $\mathrm{SD}=12.1 ;$ risperidone $20.7, \mathrm{SD}=10.3 ; t=1.32$, df 35 , $p=0.19 ; \quad \mathrm{OC}=$ amoxapine $15.2, \quad \mathrm{SD}=12.6 ;$ risperidone $20.7, \mathrm{SD}=10.3 ; t=1.35$, df $32, p=0.18$ ). After the exclusion of these six subjects, the risperidone group showed a higher mean prolactin level in the LOCF analysis than the amoxapine group $(39.1 \mathrm{ng} / \mathrm{ml}, \mathrm{SD}=24.0$ vs $21.2 \mathrm{ng} / \mathrm{ml}$, $\mathrm{SD}=22.3$ respectively; $t=2.3$, df $35, p=0.02)$ at the end point. Similar findings were observed in the OC analysis (Risperidone $39.1 \mathrm{ng} / \mathrm{ml}, \mathrm{SD}=24.0$ vs Amoxapine $21.5 \mathrm{ng} /$ $\mathrm{ml}, \mathrm{SD}=23.8 ; t=2.12$, df $32, p=0.04$ ).

While amoxapine led to a decrease in the QTc interval, risperidone showed a very slight increase, this difference was significant only in the completer's analysis $(t=2.33,37$ df, $p=0.02$ ). Nevertheless, no patient in any group had a potentially clinically significant increase in QTc interval ( $>450 \mathrm{~ms}$ and a $>10 \%$ increase from baseline) during the double-blind treatment.

Concomitant use of biperiden for the potential treatment of extrapyramidal symptoms was similar in the two treatment groups (amoxapine $n=2$; risperidone $n=1$ ). Also, the use of benzodiazepines was comparable between the amoxapine and the risperidone groups $(n=6 v s n=6$, respectively).

The incidence of adverse events was similar in both treatment groups with all being mild to moderate intensity. A total of 19 patients (10 patients in the amoxapine group and nine in the risperidone group) experienced at least one adverse event. The more frequently reported adverse events with amoxapine were constipation, diarrhea, stomachache, anxiety, and akathisia. While dry mouth, somnolence, and motor disturbances were more frequently reported in the risperidone group. Extrapyramidal side effects were reported in two patients from each treatment group. There were no suicide attempts in either group during the study.

\section{DISCUSSION}

In this study, amoxapine showed similar efficacy to risperidone for the treatment of positive, negative, and depressive symptoms of patients with schizophrenia. The response rate based on a $\geqslant 30 \%$ decrease on PANSS total score was superior to $70 \%$ in both treatment groups. The improvement on this broad set of dimensions supports the efficacy of amoxapine as an atypical antipsychotic.

Our findings are consistent with previous reports, both in preclinical data in animal models and PET studies, showing the blocking action of amoxapine of serotonin 5HT2 and dopamine D2 receptors (Greenblatt et al, 1978; Kapur et al, 1999; Wadenberg et al, 2000). They also support the previous open-label trial where we observed that $75 \%$ of patients met the criteria of response, and they also showed improvement in depressive symptoms and no significant EPS (Apiquian et al, 2003). These data suggesting an antipsychotic effect are also consistent with the observations on open clinical trials which established the efficacy of this drug in the treatment of depression with psychotic features (Anton and Burch, 1990; Anton and Sexauer, 1983). 
However, our results differ from a brief report by Fitzgerald et al (2004) of five patients treated with amoxapine in a double-blind, 8-week trial comparing the efficacy of amoxapine and olanzapine in the treatment of schizophrenic patients. In that study, no clinical improvement was observed in patients treated with amoxapine. There were important differences between the two studies that must be taken in account: First, the study was closed after including five patients per group, reporting a lack of efficacy of amoxapine. Indeed, the authors proposed that their results should be taken with caution given the small simple size. Second, the patients in that study were more chronically ill ( 9 years) than patients in this study (6 years). Third, the doses differed between the two studies, the Fitzgerald et al study used doses of amoxapine less than $200 \mathrm{mg} /$ day, meanwhile in the current study the mean dose was $228 \mathrm{mg} /$ day. This may be a critical difference given that the recommended dose for the treatment of psychotic depression is more than $200 \mathrm{mg} /$ day and the dose range recommended based on D2 receptors occupancy is also suggested to be superior to $200 \mathrm{mg} /$ day (Anton and Burch, 1990; Kapur et al, 1999).

Regarding safety data, no differences were observed on side effects (weight gain and glucose and levels) between the treatment groups. However, the risperidone group showed a higher frequency of EPS. Given the small sample size we would not want to over interpret these results, but they point to one possible area of superiority for amoxapine. The difference between the two drugs on prolactin elevation corresponds with previous reports that risperidone causes very notable levels of prolactin elevation more than other atypicals (Volavka et al, 2004), and some typical antipsychotics (David et al, 2000; Zhang et al, 2004). Amoxapine has also been associated with modest elevations in prolactin (Anton et al, 1983) as observed in this study; however, the magnitude seems to be lower. In addition, it is important to mention that none of the patients in any group reported side effects related to prolactin elevation. Concerning other side effects, its important to mention that in this study the patients treated with amoxapine presented constipation, which is related to the anticholinergic activity and has been reported in other clinical trials as equipotent to imipramine (Dugas and Weber, 1982). There were no reports of overdosing in the present study. The ingestion of doses superior to $1500 \mathrm{mg}$ of amoxapine has been associated to multiple seizures, severe metabolic acidosis, acute renal failure, and coma (Coccaro and Siever, 1985). However, reports of death with amoxapine overdosage are only about 4\% (Bishop and Kiltie, 1983). The administration of this drug should be monitored in patients with suicide risk.

The results of this study should be interpreted taking in account the small sample size and the short duration of the trial. The population in this study was early in the course of their illness, and given the Fitzgerald report, one should study a more chronic population to ensure that these results are generalizeable. Further, of the total dropouts after the first visit, three were in the amoxapine group (two for lack of efficacy, one for consent withdrawal) and one in risperidone (for nonefficacy). These numbers are too small to draw any conclusions - except that this is a trend that needs to be monitored in future studies. This was a trial designed as a proof-of-principle trial to be done in a single academic setting, and as such was not designed as a formal 'noninferiority' study. Nonetheless, the results do provide the data to plan for a definitive noninferiority study. Taking total PANSS to be the variable of greatest interest, both drugs showed an improvement (using LOCF figures, as they are more conservative) of 30.8-31.5 PANSS score, with an $\mathrm{SD}$ of 25-28. If one set a noninferiority acceptance margin as being an improvement of no less than six PANSS points inferior to risperidone - it would require anything from 80 to 100 subjects in each cell to reach a more definitive conclusion of noninferiority with the usual acceptance parameters.

In conclusion, current study demonstrates that amoxapine may be comparable to risperidone in its efficacy as an atypical antipsychotic. While our study is not definitive - it makes a strong case for further study. This is not just an academic point, but could be an issue of significant public health importance. In Mexico, where this study was conducted, access to atypical antipsychotics is restricted because of cost. The usual effective doses of olanzapine, risperidone, and aripiprazole cost anywhere from 100 to 300 USD. In contrasts, the treatment cost with generic, offpatent typical antipsychotics is in the range of \$10 USD. Therefore, atypical antipsychotics are not frequently prescribed in Mexico, and approximately $80 \%$ of the patients are treated with typical antipsychotics (Apiquian et al, 2004), while in the USA, more than $80 \%$ of the patients are treated with atypicals (Hermann et al, 2002). This lack of accessibility of atypical antipsychotics, largely attributable to price, is not only an issue in Mexico but is likely to be the reality for the majority of the worlds' patients with schizophrenia who live in low-income countries. Amoxapine is now off-patent. It can be produced at generic prices that could rival those of the typical antipsychotics. Thus, the potential exists that amoxapine may turn out to be an atypical antipsychotic for the masses. Given this potential, we urge further multicentre, large-scale testing of amoxapine, as a low-cost equal-efficacy alternative to atypical antipsychotics, especially in jurisdictions which cannot afford the more established atypicals.

\section{ACKNOWLEDGEMENTS}

We thank Ms Penny Barsoum for her help in organizing and coordinating the study. The study was supported by the grant number 107/2001 from a Theodore and Vada Stanley Foundation. SK is supported by a Canada Research Chair. RA, REU, and HN are supported by National Council of Science and Technology in Mexico.

\section{STATEMENT OF INTEREST}

None.

\section{REFERENCES}

Addington D, Addington J, Atkinson M (1996). A psychometric comparison of the Calgary Depression Scale for Schizophrenia and the Hamilton Depression Rating Scale. Schizophrenia Res 19: 205-212. 
Anton Jr RF, Burch Jr EA (1990). Amoxapine versus amitriptyline combined with perphenazine in the treatment of psychotic depression. Am J Psychiatry 147: 1203-1208.

Anton RF, Sexauer JD (1983). Efficacy of amoxapine in psychotic depression. Am J Psychiatry 140: 1344-1347.

Anton RF, Sexauer JD, Randall CL (1983). Amoxapine elevates serum prolactin in depressed men. J Affect Disord 5: 305-310.

Apiquian R, Fresan A, De la Fuente-Sandoval C, Ulloa RE, Nicolini $\mathrm{H}$ (2004). Survey on schizophrenia treatment in Mexico: perception and antipsychotic prescription patterns. $B M C$ Psychiatry 4: 12.

Apiquian R, Paez F, Loyzaga C, Cruz E, Gutiérrez D, Suárez JA et al (1997). Mexican study on the first psychotic episode: preliminary results, sociodemographic and clinical characteristics. Salud Ment 20: 1-17.

Apiquian R, Ulloa R, Fresan A, Loyzaga C, Nicolini H, Kapur S (2003). Amoxapine shows atypical antipsychotic effects in patients with schizophrenia: results from a prospective openlabel study. Schizophrenia Res 59: 35-39.

Barnes T (1989). A rating scale for drug-induced akathisia. $\mathrm{Br} J$ Psychiatry 154: 672-676.

Bishop MP, Kiltie H (1983). Neurotoxicity with amoxapine overdose: a more reasonable perspective. Drug Intell Clin Pharm 17: 131-132.

Coccaro EF, Siever LJ (1985). Second generation antidepressants: a comparative review. J Clin Pharmacol 25: 241-260.

David SR, Taylor CC, Kinon BJ, Breier A (2000). The effects of olanzapine, risperidone, and haloperidol on plasma prolactin levels in patients with schizophrenia. Clin Ther 22: 1085-1096.

Dugas JE, Weber SS (1982). Amoxapine (Asendin, Lederle Laboratories). Drug Intell Clin Pharm 16: 199-204.

Emsley RA, Oosthuizen PP, Joubert AF, Hawkridge SM, Stein DJ (1999). Treatment of schizophrenia in low-income countries. Int J Neuropsychopharmacol 2: 321-325.

Fitzgerald PB, Filia S, De Castella A, McBain N, Kapur S, Kulkarni J (2004). Amoxapine in schizophrenia: a negative double-blind controlled trial. J Clin Psychopharmacol 24: 448-450.

Greenblatt E, Lippa A, Osterberg A (1978). The neuropharmacological actions of amoxapine. Arch Int Pharmacodynam Ther 233: $107-135$.

Guy W (1976). ECDEU Assessment Manual for Psychopharmacology, Vol DHEW publication No. (ADM)76-388. National Institute of Mental Health: Rockville, Maryland, USA.

Hermann RC, Yang D, Ettner SL, Marcus SC, Yoon C, Abraham M (2002). Prescription of antipsychotic drugs by office-based physicians in the United States, 1989-1997. Psychiatr Serv 53: 425-430.

Kapur S, Cho R, Jones C, McKay G, Zipursky R (1999). Is amoxapine an atypical antipsychotic? Positron-emission tomography investigation of its dopamine 2 and serotonin2 occupancy. Biol Psychiatry 45: 1217-1220.

Kay S, Fiszbein A, Vital-Herne M, Fuentes L (1990). The positive and negative syndrome scale-Spanish adaptation. J Nerv Ment Dis 178: $510-517$.

Kinon BJ, Lieberman JA (1996). Mechanisms of action of atypical antipsychotic drugs: a critical analysis. Psychopharmacology (Berl) 124: 2-34.

Lydiard R, Gelenberg A (1981). Amoxapine - an antidepressant with some neuroleptic properties? A review of its chemistry, animal pharmacology and toxicology, human pharmacology, and clinical efficacy. Pharmacotherapy 1: 163-178.

McEvoy JP, Hogarty GE, Steingard S (1991). Optimal dose of neuroleptic in acute schizophrenia. A controlled study of the neuroleptic threshold and higher haloperidol dose. Arch Gen Psychiatry 48: 739-745.

National Institute of Mental Health (1975). Abnormal Involuntary Movement Scale (AIMS). Early Clin Drug Evaluat Unit Intercomun 4: 3-6.

Oosthuizen P, Emsley RA, Turner J, Keyter N (2001). Determining the optimal dose of haloperidol in first-episode psychosis. J Psychopharmacol 15: 251-255.

Simpson G, Angus J (1970). A rating scale for extrapyramidal side effects. Acta Psychiatr Scand Suppl 212: 11-19.

Stockmeier CA, DiCarlo JJ, Zhang Y, Thompson P, Meltzer HY (1993). Characterization of typical and atypical antipsychotic drugs based on in vivo occupancy of serotonin2 and dopamine 2 receptors. J Pharmacol Exp Ther 266: 1374-1384.

Volavka J, Czobor P, Cooper TB, Sheitman B, Lindenmayer JP, Citrome L et al (2004). Prolactin levels in schizophrenia and schizoaffective disorder patients treated with clozapine, olanzapine, risperidone, or haloperidol. J Clin Psychiatry 65: 57-61.

Wadenberg M, Sills T, Fletcher P, Kapur S (2000). Antipsychoticlike effects of amoxapine, without catalepsy, using the prepulse inhibition of the acoustic startle reflex test in rats. Biol Psychiatry 47: 670-676.

Zhang XY, Zhou DF, Cao LY, Zhang PY, Wu GY, Shen YC (2004). Prolactin levels in male schizophrenic patients treated with risperidone and haloperidol: a double-blind and randomized study. Psychopharmacology (Berl) 178: 35-40. 